Sharif University of Technology
Scientia Iranica
SCIENTIA
I RAN I CA
http://scientiairanica.sharif.edu

\title{
Attitude-based conflict management for resolving disputes over water quality of the Seymareh River in Iran
}

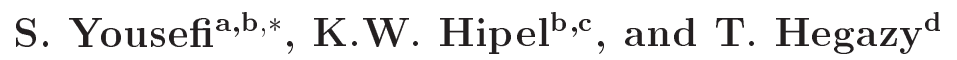 \\ a. Department of Architecture, University of Tehran, Tehran, P.O. Box 1415564583, Iran. \\ b. Department of Systems Design Engineering, University of Waterloo, Waterloo, Ontario, Post Code: N2L 3G1, Canada. \\ c. Centre for International Governance Innovation, Waterloo, Ontario, Canada; and Balsillie School of International Affairs, \\ Waterloo, Ontario, Canada. \\ d. Department of Civil Engineering, University of Waterloo, Waterloo, ON, Post Code: N2L 3G1, Canada.
}

Received 28 January 2017; received in revised form 10 January 2018; accepted 23 June 2018

\section{KEYWORDS}

Systems engineering;

Conflict;

Management;

Methodology;

Graph model.

\begin{abstract}
A strategic negotiation methodology for managing complex water-related conflicts is presented in order to consider the decision makers' attitudes. The developed approach systematically exploits the Graph Model for Conflict Resolution (GMCR) as an analytical and practical technique, and helps decision makers find the most beneficial outcomes for negotiating their disputes, assuming the competing needs, wants, and attitudes of decision makers. A real case study of a water-related dispute in Iran is used to demonstrate the implementation of the developed methodology and to emphasize the significance of decision makers' attitudes in identifying feasible negotiation outcomes for resolving complex disputes. In fact, the developed attitude-oriented methodology proposes an innovative engineering approach to help stakeholders address a wide range of conflicts, especially in complex water disputes in developing countries where human factors such as attitude play a significant role. The research can also help decision makers with the shortcomings of conventional decision making systems, such as original GMCR, through incorporating attitudes into conflict resolution tools in order to better clarify needs and interests, obtain equilibrium results, and generate more equitable solutions.
\end{abstract}

(C) 2020 Sharif University of Technology. All rights reserved.

\section{Introduction}

Water quality has become an increasing concern throughout the globe, particularly in developing countries. Due to many reasons such as the lack of a sustainable approach to water management and scarcity of water resources, the quality of water resources

\footnotetext{
*. Corresponding author. Tel.: +982161112534 E-mail addresses: sdyousefi@ut.ac.ir; s2yousef@uwaterloo.ca(S.Yousefi); kwhipel@uwaterloo.ca (K.W. Hipel); tarek@uwaterloo.ca (T.Hegazy).
}

doi: $10.24200 /$ sci. 2018.20599 has been significantly degraded. One key factor is human society. Human activities on all spatial scales impact both the quality and quantity of water [1]. Moreover, changes in land use due to human activities have negatively influenced climate and environment as well as the quantity and quality of water resources. The hydrogeological and biophysical environments are directly affected by land use changes and other socioeconomic activities that are mainly controlled by human initiatives [2].

Pollution of water resources has been the cause of many conflicts among countries and/or among communities within a country. This phenomenon is especially intensified in arid regions where many stakeholders, 
who often have conflicting objectives, interact based on their different needs and priorities. As an example, dam construction in arid and/or semi-arid countries often includes parties who are in support of building dams and other stakeholders who are opposed to it. In this regard, many experts with the natural sources background believe that major water transmission projects or dam building destruct the environment. On the other hand, many government authorities think that such projects bring tangible benefits for people within the community as well as for the whole nation. Therefore, water-related disputes are inherently complex and very hard to provide sustainable solution. Hence, flexible conflict resolution methodologies are needed in order to provide decision support in resolving them (see, for example [3-7]).

This paper strives to develop an innovative methodology for negotiating and resolving complex disputes in water and environmental projects. Because the environmental disputes are inherently complex with several decision makers DMs having different knowledge, goals, and experience backgrounds, the proposed approach incorporates human factors, such as the DMs' emotions, attitudes, fears, and anger, into the methodology. As an outcome, the challenges of traditional conflict management approaches with no human factor involvement may be overcome. The procedure will be systems-based and logically consistent. To this end, this paper is organized as follows. Conflict resolution approaches are briefly reviewed in the next section, followed by Section 3 that presents the Graph Model for Conflict Resolution (GMCR), a convenient approach for dealing with complex disputes enabling DMs to find sensible solutions. Section 4 presents a real case study and the proposed attitude-based GMCR is examined step by step for the suggested case study. Finally, some concluding remarks are presented in Section 5 .

\section{Conflict resolution approaches}

There exist several approaches to dealing with the aforementioned conflict with multiple parties. The traditional method of resolving environmental and waterrelated disputes is litigation. It can be observed that the dispute and the resolving approach are both sophisticated and very time and cost consuming [8]. The tremendous time and money spent by the disputants involved in litigation have encouraged the use of other dispute resolution methods, called Alternative Dispute Resolution (ADR) tactics [9]. The ADR tactics aim at resolving disputes with the least possible hindrance by parties from outside. A continuum of ADR presented by Richter [10] is displayed in Figure 1. Among the ADR tactics shown, negotiation tactic benefits from three main characteristics:

1. The least cost for the involved parties;

2. The least degree of hostility among involved parties;

3. Furnishing the parties involved with the highest control over the outcome of the disputes under consideration [10].

Therefore, negotiation provides the DMs, who want to make their own choices in a conflict situation, with the best alternative. As such, this paper places great emphasis on negotiation as the most preferred approach

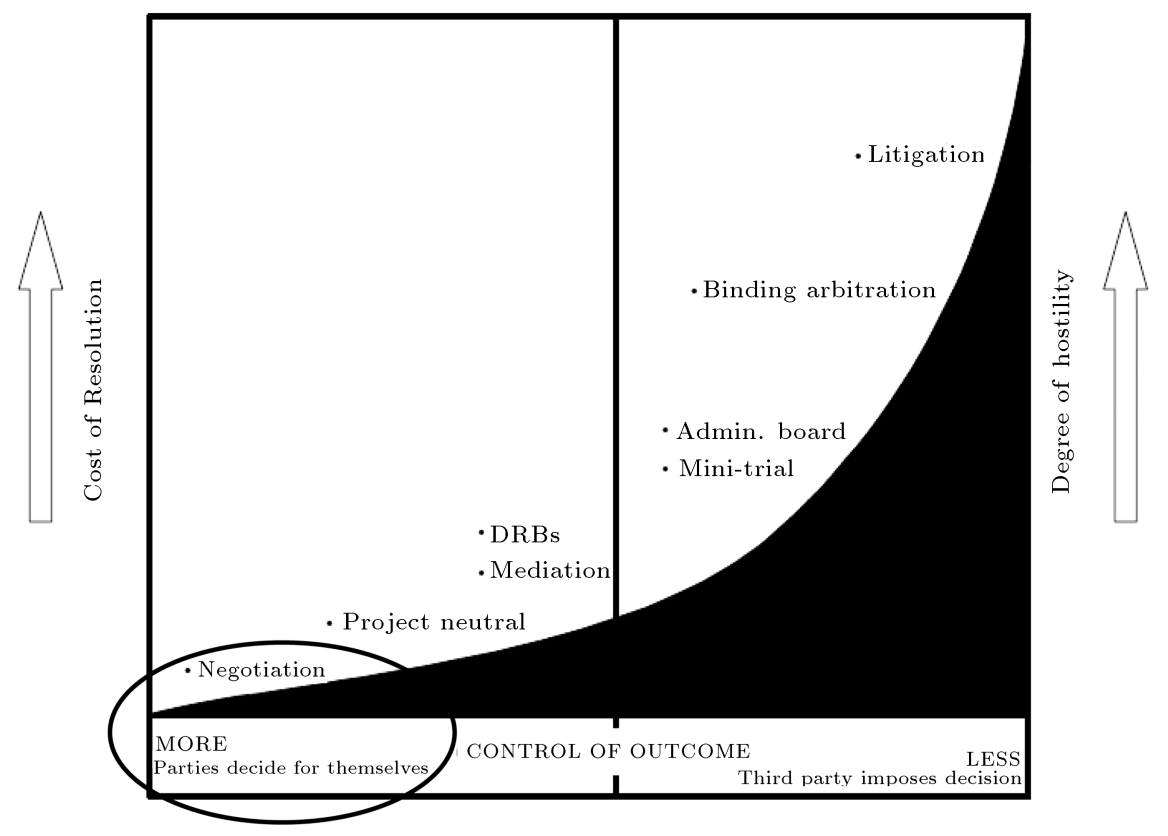

Figure 1. Dispute resolution continuum (based on Richter [10]). 
in resolving complex water-related disputes in which human factors such as attitude play a vital role. To this end, GMCR, as a means of systematically implementing a negotiation methodology at the strategic level, is introduced in the next section.

\section{Introducing Graph Model for Conflict Resolution (GMCR)}

Water and environmental disputes, such as water quality disputes, have been the subject of numerous research efforts. The main objective of these research efforts is to propose suitable techniques for resolving complex environmental disputes. As such, several formal modeling techniques and methodologies have been developed and examined in order to study and understand conflicts that have two or more DMs so that each DM can have multiple and different objectives, needs, and interests (see, for instance $[11,12]$. The GMCR [5] is particularly a methodology for modeling and analyzing the moves and countermoves of DMs in a conflict. The result is then to find stable situations for all DMs, which represent feasible resolutions to the conflict. If resolving a conflict takes place over rounds in a negotiation, GMCR can provide DMs, as negotiators, with feasible outcomes for each round of the negotiation. Therefore, DMs have a straightforward strategy to continue the rounds of their negotiation in order to eventually reach a sustainable resolution. As Kilgour [13] points out, a negotiator without a strategy has no direction to go in the negotiation path.

GMCR originates in conflict analysis an expansion of metagame theory $[14,15]$. The graph model is based on graph theory, set theory, and game theory, and uses their underlying concepts and definitions. Each DM's possible moves or countermoves from one state to other states are captured using a directed graph in which nodes represent states and arcs indicate state transitions controlled by the DM $[15,16]$. A state is defined as a potential resolution to the conflict.

\subsection{Overview}

Application of GMCR consists of two phases of modeling and analyzing that are systematically implemented, as shown in Figure 2. In the modeling phase, the conflict is structured by determining the DMs and obtaining the states for each DM, the possible state transitions controlled by the DMs, and each DM's relative preferences with respect to the states [5]. Regarding the analysis phase, the stability of each state from each DM's perspective is examined and the appropriate states are determined. This phase is aimed at determining stable states across all DMs that represent potential resolutions of the conflict [5]. The essential parts of a graph model include the DMs and the options available to each DM as well as each DM's relative preferences. In general, a DM may exercise any combination of the options they control to create a strategy. When every DM has selected a strategy, a state is created [17].

One key feature of GMCR is to assist DMs to find the right direction in the decision making process. Kilgour [13] describes that GMCR provides an understanding of and insight into strategic decisions made by DMs, and therefore, DMs can benefit from the strategic advice provided by GMCR. The most beneficial decisions will be made at the strategic level and GMCR provides a reliable platform for the DMs to make such key decisions during negotiation process. Certainly, once the right path or strategy of decision making is selected, beneficial decision making tactics are better determined.

\subsection{Stability analysis}

The purpose of stability analysis is to determine the stability of states for DMs using different solution concepts, also called stability definitions (listed in Table 1). Nash stability $[18,19]$ presents a situation where a DM thinks of only one step ahead. General metarationality (GMR) [14] and sequential stability (SEQ) [15] present a situation in which the DM considers exactly two steps forward, whereas in symmetric metarationality (SMR) [14], the DM takes into account three steps forward by assessing available escapes from any sanc-

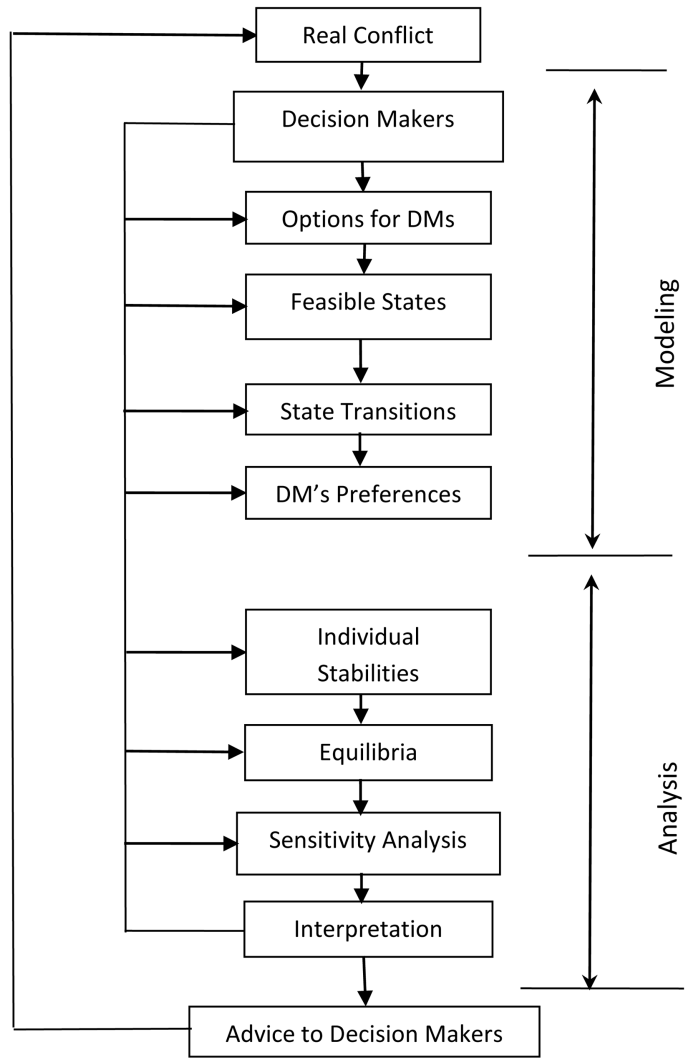

Figure 2. Systematic procedure for applying GMCR [17]. 
Table 1. Solution concepts used in GMCR $[15,7]$.

\begin{tabular}{|c|c|c|c|c|c|}
\hline \multirow[b]{2}{*}{$\begin{array}{l}\text { Stability } \\
\text { type }\end{array}$} & \multirow[b]{2}{*}{ Description } & \multicolumn{4}{|c|}{ Characteristics } \\
\hline & & Foresight & $\begin{array}{l}\text { Knowledge } \\
\text { of } \\
\text { preference }\end{array}$ & $\begin{array}{l}\text { Strategic } \\
\text { risk }\end{array}$ & Disimprovement \\
\hline Nash (R) & $\begin{array}{l}\text { Focal DM (decision maker) has } \\
\text { no unilateral improvements. }\end{array}$ & Low & Own & Ignores risk & Never \\
\hline $\begin{array}{l}\text { General } \\
\text { metarationality } \\
\text { (GMR) }\end{array}$ & $\begin{array}{l}\text { Focal DM's unilateral improvements } \\
\text { are all sanctioned by the subsequent } \\
\text { unilateral moves of other DMs. }\end{array}$ & Medium & Own & $\begin{array}{l}\text { Avoids risk; } \\
\text { conservative }\end{array}$ & $\begin{array}{c}\text { By } \\
\text { opponents }\end{array}$ \\
\hline $\begin{array}{l}\text { Symmetric } \\
\text { metarationality } \\
\quad(\text { SMR })\end{array}$ & $\begin{array}{l}\text { Focal DM's unilateral improvements } \\
\text { are sanctioned, even after its } \\
\text { responses. }\end{array}$ & Medium & Own & $\begin{array}{l}\text { Avoids risk; } \\
\text { conservative }\end{array}$ & $\begin{array}{c}\text { By } \\
\text { opponents }\end{array}$ \\
\hline $\begin{array}{l}\text { Sequential } \\
\quad(\text { SEQ })\end{array}$ & $\begin{array}{l}\text { Focal DM's unilateral improvements } \\
\text { are all sanctioned by the subsequent } \\
\text { unilateral improvements of other DMs. }\end{array}$ & Medium & All & $\begin{array}{l}\text { Takes some } \\
\text { risks; } \\
\text { strategies }\end{array}$ & Never \\
\hline $\begin{array}{l}\text { Limited-move } \\
\qquad\left(L_{h}\right)\end{array}$ & $\begin{array}{l}\text { Focal DM prefers not to move, based } \\
\text { on the assumption that all DMs act } \\
\text { optimally over up to } h \text { state transitions. }\end{array}$ & Variable & All & $\begin{array}{l}\text { Accepts risk; } \\
\text { strategies }\end{array}$ & Strategic \\
\hline $\begin{array}{l}\text { Non-myopic } \\
\qquad(\mathrm{NM})\end{array}$ & $\begin{array}{l}\text { Limiting case of limited move stability } \\
\text { as maximum number of state transitions } \\
\text { (h) increases to infinity. }\end{array}$ & High & All & $\begin{array}{l}\text { Accepts risk; } \\
\text { strategies }\end{array}$ & Strategic \\
\hline
\end{tabular}

tions that may be imposed by the opponents or other DMs. A disimprovement refers to a DM's movement to a less preferred state in order to reach a more preferred state eventually, or to block the unilateral improvements of other DMs $[11,12]$. With respect to both Nash and sequential stabilities, disimprovements are never permitted, meaning that a DM cannot take one step backward, while in general and symmetric metarationality, disimprovements by the opponents for the purpose of sanctioning are allowed along with improvement to equally preferred states. Because one or more of the aforementioned solution concepts may be suitable for different DMs, the states that are stable under many solution concepts are considered to have strong stability [20,21]. Furthermore, the states that are stable under one solution concept are considered as the ones with relatively weak stability. Therefore, it is important to consider more than one kind of solution concept for each DM in order to ensure a robust prediction for the conflict resolution. Further discussion can be found in [5] and papers in the book edited by Hipel [11] and Hipel [12].

\subsection{How to present attitude in GMCR}

Although GMCR is a great approach to resolving complex disputes, it can be further improved by incorporating human factors in its methodology. Therefore, attitudes of DMs, as a key human factor, are introduced within the paradigm of GMCR. Analysts, who are using attitude-based GMCR, benefit from this incorporation because the resulting outcomes are more realistic. In other words, the outcomes show how changes in the negotiators' attitudes influence changes in negotiation outcomes.

Attitudes of DMs are formally defined by Inohara et al. [22] and represented in a matrix format. Table 2 presents the attitudes between two DMs $i$ and $j$ by "e", in which the table cells can take a value of "+", "0", or " ", indicating a positive, neutral, or negative attitude, respectively. For instance, Table 2 represents 
Table 2. Attitudes presentation in GMCR [21].

\begin{tabular}{ccc}
\hline Decision maker & $\boldsymbol{i}$ & $\boldsymbol{j}$ \\
\hline$i$ & $e_{i i}=+$ & $e_{i j}=0$ \\
$j$ & $e_{j i}=0$ & $e_{j j}=+$ \\
\hline
\end{tabular}

a situation between the DMs $i$ and $j$ in which they have positive attitudes $(+)$ towards themselves, because $e_{i i}=+$ and $e_{j j}=+$, and have neutral attitudes towards one another because $e_{i j}=0$ and $e_{j i}=0$ [7]. It is assumed in this research that each DM logically has a positive attitude towards itself.

\section{A real-life case study}

Some years ago, a complex dispute took place among two major DMs in Iran, a country located in an arid and somehow semiarid region with a growing need of water for different purposes. In order to address these challenges, Iran has started to build dams to make artificial reservoirs to keep water for various purposes such as drinking, agriculture, and producing electricity (hydropower). Iran has tried to expand its renewable energy projects and to this end, a fundamental plan is developed for hydropower projects in the three main basins: Karun, Karkheh, and Dez [23]. Although these huge projects are of increasing demands, they may have negative impacts on the surrounding environment. There are sometimes opposition groups who ask governmental authorities to better respect environmental considerations.

\subsection{Dispute background}

The dispute between the two DMs was about water pollution of the Seymareh Dam reservior, located in the Karkheh River Basin as displayed in Figure 3. The dam

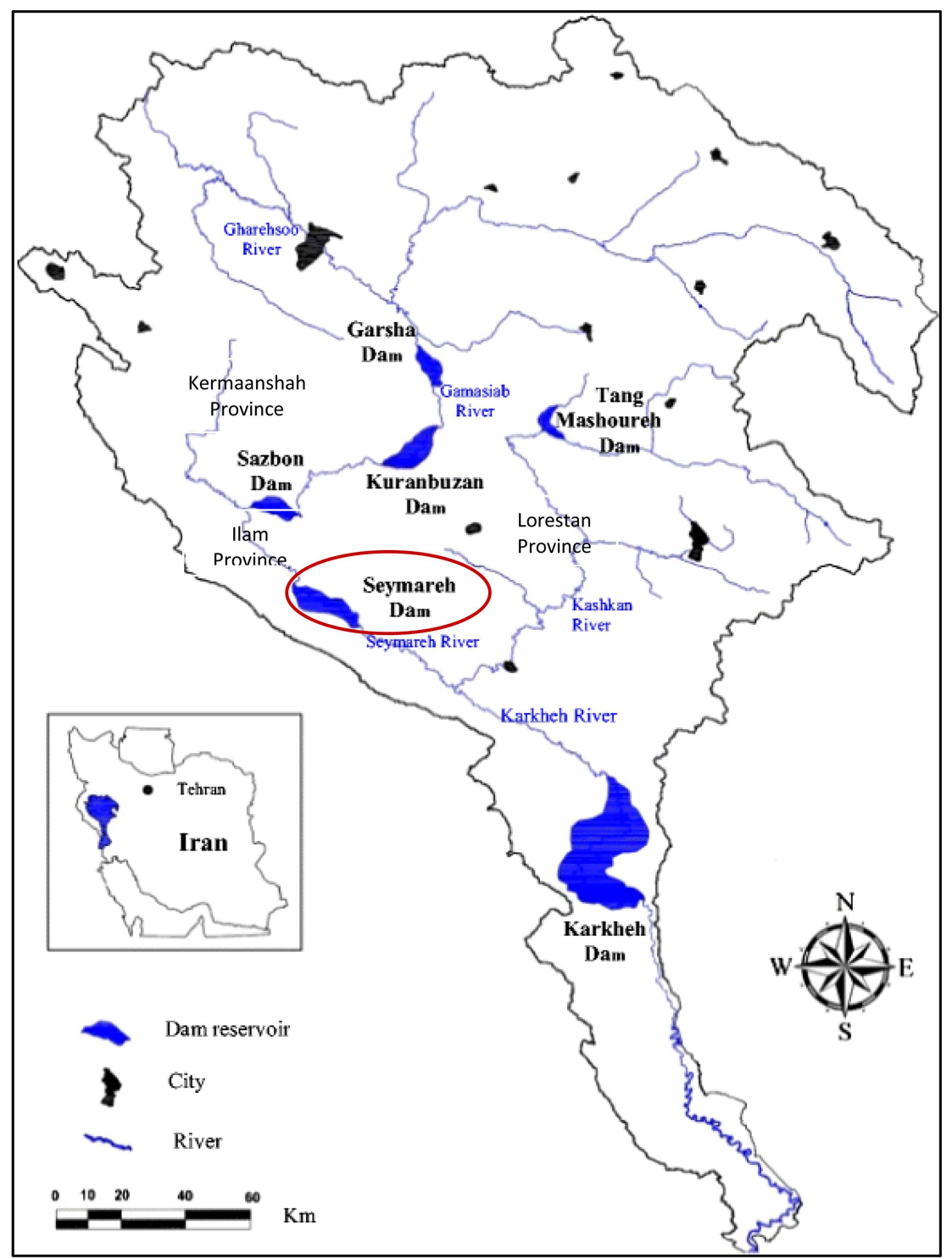

Figure 3. Seymareh Dam located in Karkheh Basin in Iran (IWPCO [24]). 
is located in the south west of Iran and is constructed in the Seymareh River, which is created from joining of the Ghareh Soo and Gamasyab Rivers. The Seymareh Dam also consists in a huge hydropower plant and has three main purposes:

a) Producing 684 GWH of energy annually;

b) Controlling and adjusting river surface flows;

c) Providing flood control facilities for the region downstream of the dam [24].

It should be mentioned that Seymareh Dam and Karkheh Dam are under operation and the rest of dams shown in Figure 3 are under study.

This dam and its reservoir cover a huge surface area of $66 \mathrm{~km}^{2}$ and contain around 3000 million cubic meters of water, so the project is affecting a considerable area of the neighboring lands that are now under the water after the dam water impoundment [24].

As shown in Figure 3, the Seymareh River passes through many residential, agricultural, and industrial areas and communities living along the two branches of the main Seymareh River, namely Kashkan River and Seymareh River, and as such, due to the lack of sufficient water and wastewater treatment facilities, many wastes are poured to the river. When entering the Seymareh Dam reservoir, the water is heavily polluted due to the wastewater discharged into the river from industrial, agricultural, and residential activities. Such intensified water pollution in the dam reservoir has created many problems for the dam owner who spent a large amount of time and costs to solve them. The dam owner believes that other stakeholders should be blamed for this conflict and inquires why he should pay for mistakes that the others are in charge for. The owner claims that the tasks of preventing, treating, and at least mitigating the water pollution are not being accomplished in upstream. On the other hand, no one in the upstream communities accepts the blame and everyone wants to blame others. "Who is to be blamed for water pollution" is the subject of the longstanding conflict. If the dam owner and upstream local communities are considered as the stakeholders in this case study, lack of suitable and sufficient communication and cooperation among them has become one of the main sources of conflict and even the conflict expansion.

\subsection{Who are involved in the conflict}

This case study is a real-life conflict that has been undergone for a long time and for the purpose of analyzing and studying this important case, the identities of the main stakeholders are kept confidential and anonymous. Therefore, "CO1" denotes the dam owner who has designed, constructed, and operated the project. On the other hand, because the whole aforementioned communities are located and living in the upstream province, "CO2" denotes the province mainly blamed for the pollution of the Seymareh River. It should be clarified that studying and analyzing as well as the resulting outcomes of this complex case are of personal opinion of the authors of this paper and they have nothing to do with any obligations of the stakeholders in order to hold them responsible for or exempt them from the results. The authors believe that it is beneficial to study the real-life conflict cases using GMCR and show its capabilities and abilities in solving complex disputes, particularly environmental disputes. The consequences of such studies are to better realize the nature of conflict and to provide strategic insights for resolving them.

In order to get familiar with the conflict growth and evolvement, a brief background is explained here. CO1 strongly believes that CO2 has caused the conflict and $\mathrm{CO} 2$, on the other hand, thinks that CO1 is wrong and the reservoir had already been polluted and the amount of pollution created upstream does not have much effect. It is obvious that the CO2's needs and wants are different from those of CO1 and it interprets the dispute in a different manner. CO2 believes that other adjacent provinces pollute the river as well and thus, it is the wrong target for blame by CO1. In addition, $\mathrm{CO} 2$ protests that why CO1 did not completely remove harmful materials and hazardous objects from the dam reservoir prior to the beginning of water impoundment. This neglect has been the main source of water pollution in CO2's opinion.

CO1 believes that other provinces have little effect on pollution and claims that CO2 shifts the blame, because major sources of pollution are produced within CO2's borders and nothing has been done by CO2 to prevent or at least mitigate the sources of pollution within its borders. As it can be observed, this dispute is very complicated and therefore, we intend to apply GMCR in two main phases. First, the disputes are going to be modeled and then, they will be analyzed in systematic steps, as shown in Figure 2, and explained one by one in the following.

Step 1: DMs and their options are determined. After determining DMs and exploring their disputes, the DMs' options are discussed as the first step of the modeling stage. Based on various investigations, it can be stated that $\mathrm{CO} 1$ can choose one among three options:

1. Taking the case to court and following up the litigation process;

2. Sharing partial costs associated with the water treatment of the basin; or

3. Starting the remediation process of the reservoir itself. 
Certainly, every choice has its own pros and cons. The first choice (litigation) may result in a winning outcome but is very lengthy and has the risk of a useless waiting time having a very high cost. The second choice may be costlier, yet may improve the water quality sooner through positive cooperation. The third choice of $\mathrm{CO} 1$ is capable to improve the quality of water in the reservoir but may not be easy to exactly obtain the amount to pay.

With respect to the second $\mathrm{DM}(\mathrm{CO} 2)$, two choices can be made:

1. Remaining at the status quo and doing nothing to make the conflict either better or worse; or

2. Receiving partial financial support in order to prevent wastewater pouring into the Seymareh River.

Here is how the two choices of $\mathrm{CO} 2$ can be justified. CO2 perceives that the dam and its hydropower plant are not built within the territory of its province and hence, no tangible benefits, such as job creation, irrigation, and flood control, are achieved by the communities. Moreover, the neighboring provinces are benefiting from the dam and its reservoir, whereas CO2 only suffers from drawbacks such as changes to its ecosystem. Therefore, creating incentives to CO2 to mitigate the pollution is not easy. Regarding the second choice of $\mathrm{CO} 2$, if financial support is provided, then $\mathrm{CO} 2$ is encouraged to build treatment facilities on its borders and start treating the polluted water. The DMs' choices are shown in Table 3.

Step 2: Determining feasible states. A state is defined as a condition (status) of a conflict. It is created by the combination of DMs' choices. In this case study, for example, state 1 (Table 3 ) is made by a combination of "Y" (stands for Yes, indicating the choice is taken by $\mathrm{DM}$ ) and "N" (stands for No, indicating the choice is not taken by DM) of the DMs' choices. In other words, CO1 does take the case to court (litigation), does not share the costs, and does not make the treatment of reservoir and $\mathrm{CO} 2$ does continue polluting the river and does not receive partial financial support for water treatment.

DMs can either reject or accept each of the options in the conflict. Since there are totally five choices, as shown in Table 3 , the number of states equals 32 (i.e., $2^{\wedge}$ ). Among the 32 states, 16 are infeasible states and therefore, the total number of feasible states equals 16 . Table 3 displays the feasible states in this case study. Infeasible states are the states that cannot logically take place and are mutually exclusive for DMs. For example, it is not logically possible that all DMs do not select any option; thus, a state with all "N" in a column in Table 3 is an infeasible state and it is removed. Infeasible states and the methodology of removing them are presented in a book by Fraser and Hipel [15].

Step 3: Integration of graph model representation and state ranking of DMs. After determining the feasible states in Table 3, the graph model of the states for DMs is developed, as shown in Figure 4(a) and (b) for CO1 and CO2, respectively. States are shown by circles and moves between states are modeled by arcs. As shown in Figure 4, each DM has the choice of reversible transit among all their own states based on the moves of the opponent DM. In other words, selection of the states by a DM is a dynamic action based on the current condition of the conflict, new decision, and changes of perceptions. For example, one possible move for CO1 is among states $6,7,8,9,10$, and 11 provided that the options of $\mathrm{CO} 2$ remain unchanged (i.e., "N" and "Y" for its two choices, shown in the middle section in Table 3 ). The same graph model is developed for CO2' moves and shown in Figure 4(b).

The ordinal states ranking of DMs is displayed in Figure 4(c). States ranking basically represents how DMs prefer one state to other feasible states in an

Table 3. DMs, their options, and feasible states.

\begin{tabular}{|c|c|c|c|c|c|c|c|c|c|c|c|c|c|c|c|c|c|}
\hline \multirow{2}{*}{ DMs } & \multirow[t]{2}{*}{ Options } & \multicolumn{16}{|c|}{16 feasible states } \\
\hline & & 1 & 2 & 3 & 4 & 5 & 6 & 7 & 8 & 9 & 10 & 11 & 12 & 13 & 14 & 15 & 16 \\
\hline \multirow{3}{*}{ CO1 } & 1) Litigation & $\mathrm{Y}^{\mathrm{a}}$ & $\mathrm{N}^{\mathrm{b}}$ & $\mathrm{N}$ & $\mathrm{Y}$ & $\mathrm{N}$ & $\mathbf{Y}$ & $\mathbf{N}$ & $\mathbf{N}$ & $\mathbf{Y}$ & $\mathbf{N}$ & $\mathbf{N}$ & $\mathrm{Y}$ & $\mathrm{N}$ & $\mathrm{N}$ & $\mathrm{Y}$ & $\mathrm{N}$ \\
\hline & 2) Share costs & $\mathrm{N}$ & $\mathrm{Y}$ & $\mathrm{N}$ & $\mathrm{N}$ & $\mathrm{Y}$ & $\mathbf{N}$ & $\mathbf{Y}$ & $\mathbf{N}$ & $\mathbf{N}$ & $\mathbf{Y}$ & $\mathbf{N}$ & $\mathrm{N}$ & $\mathrm{Y}$ & $\mathrm{N}$ & $\mathrm{N}$ & $\mathrm{Y}$ \\
\hline & 3) Reservoir treatment & $\mathrm{N}$ & Y & $\mathrm{Y}$ & $\mathrm{Y}$ & $\mathrm{N}$ & $\mathbf{N}$ & $\mathbf{Y}$ & $\mathbf{Y}$ & $\mathbf{Y}$ & $\mathbf{N}$ & $\mathbf{N}$ & $\mathrm{N}$ & $\mathrm{Y}$ & $\mathrm{Y}$ & $\mathrm{Y}$ & $\mathrm{N}$ \\
\hline \multirow{3}{*}{$\mathrm{CO} 2$} & 4) Continue & $\mathrm{Y}$ & Y & $\mathrm{Y}$ & $\mathrm{Y}$ & $\mathrm{Y}$ & $\mathbf{N}$ & $\mathbf{N}$ & $\mathbf{N}$ & $\mathbf{N}$ & $\mathbf{N}$ & $\mathbf{N}$ & $\mathrm{N}$ & $\mathrm{N}$ & $\mathrm{N}$ & $\mathrm{N}$ & $\mathrm{N}$ \\
\hline & 5) Partial support & $\mathrm{N}$ & $\mathrm{N}$ & $\mathrm{N}$ & $\mathrm{N}$ & $\mathrm{N}$ & $\mathbf{Y}$ & $\mathbf{Y}$ & $\mathbf{Y}$ & $\mathbf{Y}$ & $\mathbf{Y}$ & $\mathbf{Y}$ & $\mathrm{N}$ & $\mathrm{N}$ & $\mathrm{N}$ & $\mathrm{N}$ & $\mathrm{N}$ \\
\hline & Graph model (Figure 4) & \multicolumn{5}{|c|}{$\begin{array}{l}\text { Figure } 4(\mathrm{a}) \text { : } \\
\text { Left diagram }\end{array}$} & \multicolumn{6}{|c|}{$\begin{array}{c}\text { Figure 4(a): } \\
\text { Middle diagram }\end{array}$} & \multicolumn{5}{|c|}{$\begin{array}{l}\text { Figure 4(a): } \\
\text { Right diagram }\end{array}$} \\
\hline
\end{tabular}

\footnotetext{
${ }^{a}$ Y: Yes; ${ }^{b} \mathrm{~N}:$ No
} 
ordinal manner in a conflict. For each DM, it is sorted from the most preferred states on the left to the least preferred states on the right. With respect to CO1, for example, the most preferred or desired state of this particular conflict is state 15 , which means that when partial support is provided, CO2 receives financial support and immediately begins the treatment of the Seymareh River entering the dam reservoir. On the other hand, state 2 is the least preferred or desired state for CO1, which means that CO1 does nothing or takes no action even though the case is not taken to court and some costs are accepted by CO1. In order to better interpret CO1's state ranking, CO1 prefers CO2 to be motivated to stop polluting the Seymareh River and plan to provide some facilities for treating wastewaters produced by communities along the river before pouring to the river. To this extent, CO1 as the owner of the dam and power plant under operation is aware of the lengthy process of taking the case to court and accordingly, it would choose the states with litigation at the end of states ranking.

Similar explanation is provided for $\mathrm{CO} 2$, whose most preferred condition of the conflict is state 13 . It means CO2 really prefers that while it has taken no action, CO1 does not take the case to the court, and it shares costs with other organizations to come up with solutions to stop polluting the river. Meanwhile, CO2's least preferred situation of the conflict is state 12 , in which CO2 is forced to remediate the wastewater while CO1 accuses $\mathrm{CO} 2$ in the court and it starts remediating the reservoir water pollution. In other words, CO2 basically feels that litigation is not a good choice neither for itself nor for CO1 and as such, it hesitates to pick up those choices.

Step 4: Developing reachable lists. In general, a DM can change its position from one state to another. If there are many states, then the DM has a list of options to move to (in one step) from one specific starting state to other feasible states. Such a list is called the reachable list, which is mathematically defined as follows [5,25]: for $i \in N$ and $s \in S, \mathrm{DM}_{i}$ 's reachable list from state $s$ is the set $\left\{t \in S \mid(s, t) \in A_{i}\right\}$, denoted by $R_{i}(s) S$, where " $A_{i}$ " is the total number of states. For the case study in this research, Table 4 shows the reachable list for each DM. The reachable lists of the DMs are used to determine each DM's unilateral improvement states when their attitudes are incorporated into their decision. As such, each DM has two choices: either to move to another state or to remain in the current state.
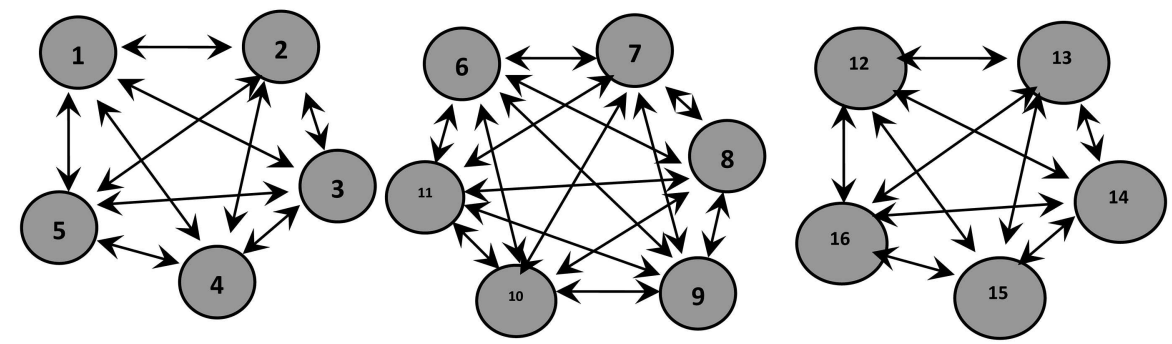

(a) CO1's moves
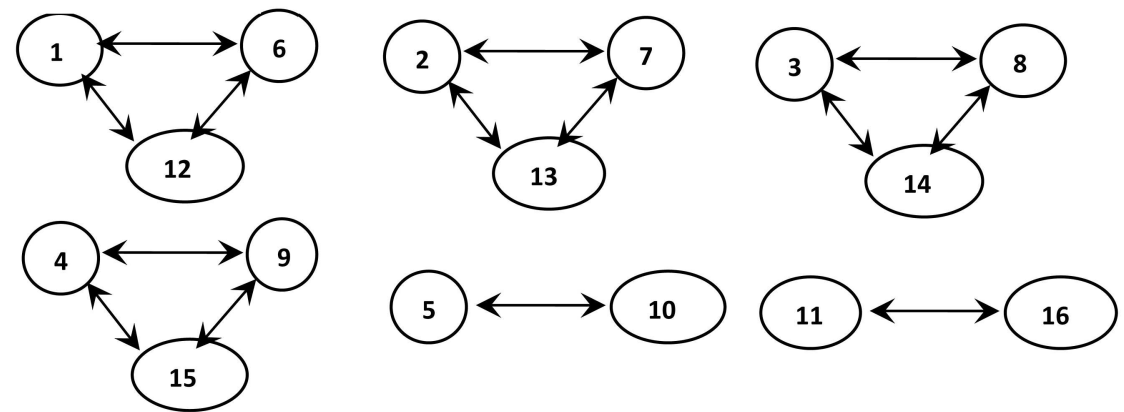

(b) CO2's moves

\begin{tabular}{|c|c|c|c|c|c|c|c|c|c|c|c|c|c|c|c|c|}
\hline \multirow{3}{*}{$\begin{array}{l}\text { DMs } \\
\text { CO1 }\end{array}$} & \multicolumn{16}{|c|}{ Ordering of States from Most to Least Preferred } \\
\hline & \multicolumn{4}{|c|}{ Most Preferred } & \multicolumn{5}{|c|}{------------------------- $\rightarrow$} & \multicolumn{3}{|c|}{ Least } & \multicolumn{3}{|c|}{ Preferred } & \\
\hline & 15 & 16 & 7 & 6 & 8 & 5 & 11 & 10 & 12 & 9 & 14 & 4 & 1 & 13 & 3 & 2 \\
\hline $\mathrm{CO} 2$ & 13 & 2 & 3 & 6 & 16 & 7 & 15 & 10 & 14 & 11 & 8 & 1 & 4 & 5 & 9 & 12 \\
\hline
\end{tabular}

(c) DMs' ordinal state preferences

Figure 4. Graph model and state ranking integrated for DMs. 
Table 4. DMs' reachable lists.

\begin{tabular}{ccc}
\hline State & $\boldsymbol{R}_{(\mathrm{CO} 1)}$-state & $\boldsymbol{R}_{(\mathrm{CO} 2)}$-state \\
\hline 1 & $2,3,4,5$ & 6,12 \\
2 & $1,3,4,5$ & 7,13 \\
3 & $1,2,4,5$ & 8,14 \\
4 & $1,2,3,5$ & 9,15 \\
5 & $1,2,3,4$ & 10 \\
6 & $7,8,9,10,11$ & 1,12 \\
7 & $6,8,9,10,11$ & 2,13 \\
8 & $6,7,9,10,11$ & 3,14 \\
9 & $6,7,8,10,11$ & 4,15 \\
10 & $6,7,8,9,11$ & 5 \\
11 & $6,7,8,9,10$ & 16 \\
12 & $13,14,15,16$ & 1,6 \\
13 & $12,14,15,16$ & 2,7 \\
14 & $12,13,15,16$ & 3,8 \\
15 & $12,13,14,16$ & 4,9 \\
16 & $12,13,14,15$ & 11 \\
\hline
\end{tabular}

Step 5: Performing attitude-based stability analysis. Stability analysis is a key process in the analysis stage of GMCR and it is defined as systematic study of potential moves and countermoves made by DMs who negotiate for more preferred positions during a conflict evolution. They attempt to reach the most likely resolution to the conflict that is more preferred for them [6]. The solution concepts, listed and defined in Table 1, are used to conduct the stability analysis. In order to further expand the conventional stability analysis introduced by Fraser and Hipel [15], attitudes of DMs are incorporated into the procedure of the stability analysis and as such, attitude-based stability analysis is defined. In other words, the moves and countermoves of DMs in a conflict are influenced by attitudes of DMs and accordingly, the outcome of the conflict may change. More information in this regard can be found in [7].

The DMs' reachable list, developed and listed in Table 4, is used to perform the stability analysis when the attitudes of the DMs are incorporated. The following three solution concepts are used in this paper [15].

1. Nash: In this situation, a DM does not have any Unilateral Improvement (UI) to make from the state. In other words, the last selected strategy is the best that can be selected given the strategy selection of the other DMs. A UI is a state to which a particular DM can unilaterally move if the strategy is changed, assuming that the other DM's strategy remains the same. The Nash (rational) state is considered as a stable outcome denoted by "Nash" [15];

2. Unstable: With respect to this solution concept, each DM has at least one UI from which the other DMs cannot take any credible actions that result in a less preferred state for the given DM. An unstable outcome is denoted by "U" [15];

3. Sequentially sanctioned: Regarding this situation, for all UIs available to one DM, credible actions can be considered and taken by the other DMs in a way that a less preferred state than the one from which the DM is improving will result from them. A credible action is defined as an action that results in a more preferred state for the given DM taking the action. The possibility that a worse state could result from changing strategy by a DM deters them from unilaterally attempting a position improvement and induces a stability type labeled as "SEQ" [15].

In order to conduct and accomplish the stability analysis in this case study and demonstrate how the DMs' attitudes influence the conflict and change the outcomes, three attitude scenarios are presented below. It is assumed that each DM has positive attitude towards itself in every scenario, which is a logical assumption.

Scenario 1: DMs possess neutral attitudes towards each other. Scenario 1 presents a situation in which the DMs have positive attitudes towards themselves and neutral attitudes towards each other. Figure 5 shows a tableau that represents the analysis process and includes three parts: the top part presents the stability analysis of the states for CO1; the middle section gives the stability analysis of the states for $\mathrm{CO} 2$; and the bottom part provides the equilibrium results. As shown in the tableau, the DM section consists of three rows: the list of state ranking (preferences) for the DM, possible moves from each state to any other for the DM, and finally, the row pertaining to stability types. The tableau represents a framework that can assist analysts who want to study the moves and countermoves by the DMs involved in a systematic manner. There are some arrows heading down from the state ranking. These arrows indicate the possible moves that can put a DM in a preferred decision state [7]. The arrow from state 8 for CO1, for example, indicates that $\mathrm{CO} 1$ can move to states 7 and 6 , which are preferred to state 8 (according to CO1's ranking). Although CO1 can move from state 8 to state 6,7 , 9,10 , or 11 (as shown in row 8 of Table 4), only states 6 and 7 are preferred to state 8 , while states 9,10 , and 11 are ranked lower. Therefore, only states 7 and 6 appear under state 8 in Figure 5, which is 


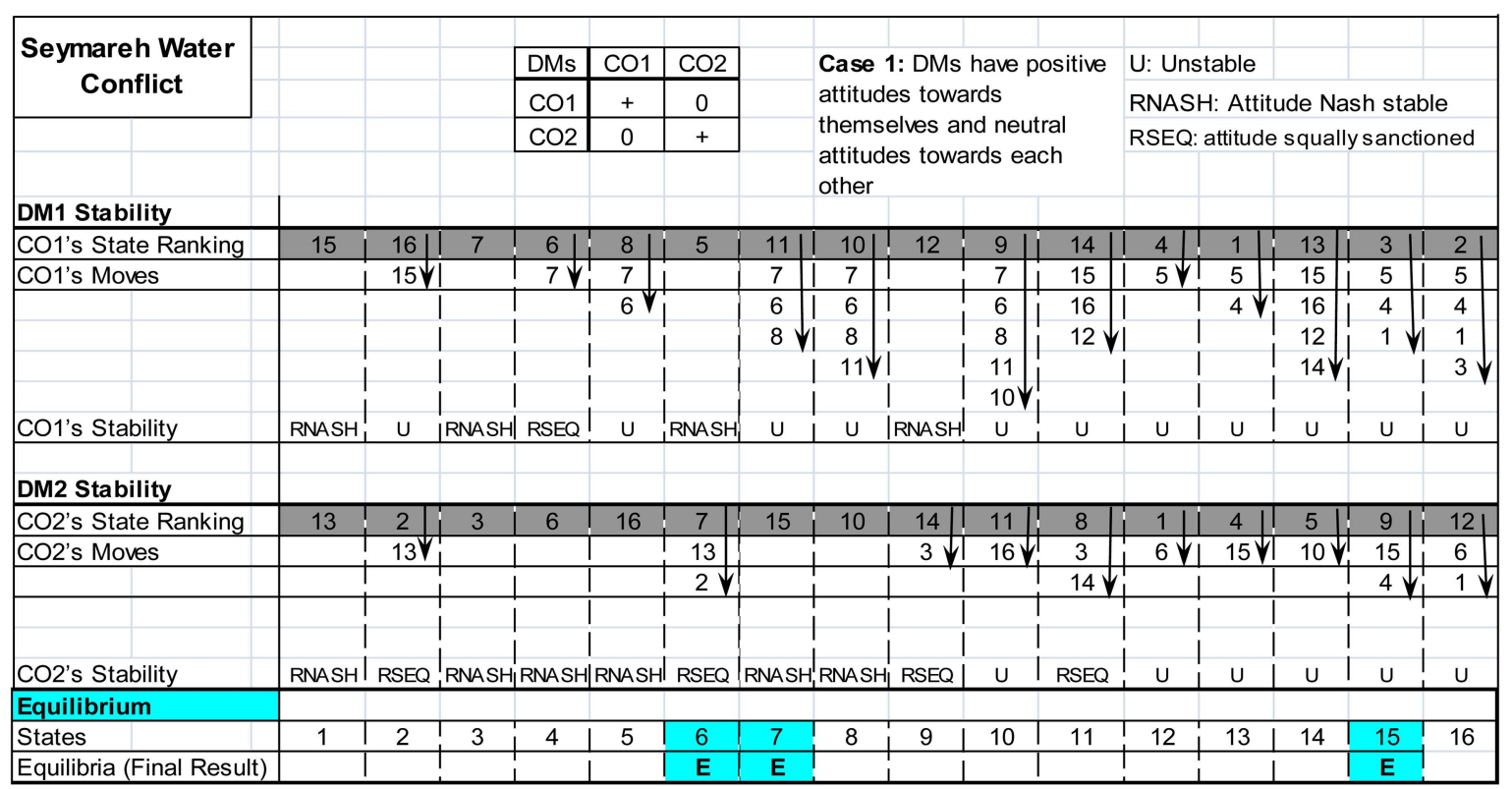

Figure 5. Stability analysis tableau with rational attitudes of DMs towards each other.

consistent with CO1's positive attitude towards itself. In a similar manner, Figure 5 presents the moves from different decision states in the state ranking to other states, which are consistent with the attitudes of the DMs in Scenario 1.

Upon determining the possible moves of every DM, the type of stability for each state and each DM is determined using Figure 5. The Nash stability (first type in Table 1), for instance, is reviewed. The analysis begins with the state ranking (first row for CO1) and examining the states which do not have arrows (i.e., cannot be improved). States 15, 7, 5, and 12 for CO1 and states $13,3,6,16,15$, and 10 for CO2 are Nash stable ones, and they are marked with "RNash" (i.e., attitude-based Nash stability) as shown in Figure 5. Likewise, other types of stability are obtained and marked in the third row for each DM (DM's stability row in Figure 5 ). The stability of state 8 for $\mathrm{CO} 1$, for example, is studied. In order to move from state 8, CO1 has two choices: states 7 and 6 . If CO1 wants to move from state 8 to state 7 , the examination of $\mathrm{CO} 2$ 's moves reveals that $\mathrm{CO} 2$ can respond by moving from 7 to 13 or to 2. However, in CO1's state ranking, both 2 and 13 are not preferred to 8 ; thus, $\mathrm{CO} 1$ is deterred from improving from 8 to 7 . However, if $\mathrm{CO} 1$ wants to move from 8 to $6, \mathrm{CO} 2$ cannot reply, because state 6 is Nash stable for $\mathrm{CO} 2$; thus, CO1 has the option to unilaterally move to 6 . Therefore, state 8 is unstable and a "U" is marked underneath 8 in the stability analysis row for DM1. As shown in Figure 5, there are states that have no types of stability, which are called unstable states. Therefore, it is possible for the DMs to move from these unstable states to preferred states that are more beneficial.
Examination of the stability of state 8 for $\mathrm{CO} 2$ indicates that it can move to 3 or 14 . Moving from 8 to 3 by $\mathrm{CO} 2$ will face the countermove of $\mathrm{CO} 1$ from 3 to 5,4 , or 1 , which are all not preferred to 8 for $\mathrm{CO} 2$. Similarly, if CO2 wants to move from 8 to 14 , then CO1 can make a countermove from 14 to 12 , which is not preferred to 8 for CO2. Therefore, CO2 would not prefer to move from state 8 and this state is called sequentially sanctioned for CO2 and "RSEQ" is written below 8 in CO2's stability analysis.

All stability types for every DM and state are examined and each stability type is marked below each state. Equilibrium or final results are assessed and indicated at the bottom part of Figure 5 after the completion of the process. For example, states 6, 7, and 15 are indicated by "E," which means that these states are stable for both DMs due to some types of stability they show for all DMs involved. In terms of interpretation of the states, state 7 , for example, means that CO1 does not proceed with litigation, shares costs with other stakeholders to remediate the river in the upstream, and provides treatment for the dam reservoir, while $\mathrm{CO} 2$ does not continue polluting the river in upstream and receives financial supports to carry out actions for cleaning the river (Table 3 ). As defined by Fraser and Hipel [15], if a state proves to have some types of stability for all DMs after examining the moves and countermoves by all DMs, this state is named and represented as an equilibrium state, which constitutes a possible resolution to a dispute. Based on the definition of equilibrium state, the remaining states are named and considered as unstable states for at least one of the DMs and, thus, they cannot be considered as possible resolutions to the conflict. 
The final resulting outcome of Scenario 1 indicates that the decision states 6,7 , and 15 are equilibrium states, or possible strategic resolutions, based on the DMs' neutral (rational) attitudes towards each other. The second scenario considers another possible attitude of DMs, as discussed below.

Scenario 2: DMs possess negative attitudes towards each other. It was examined in the first scenario that the DMs possessed neutral attitudes towards each other. In the second scenario, a situation is assumed in which the DMs change their attitudes to negative attitudes towards each other while their attitudes towards their own remains positive. The process of stability analysis is described below and shown in Figure 6.

Underneath the DMs' state ranking, the beneficially preferred moves are listed in Figure 6. Among these moves, some are crossed out by an "X" (Figure 6), meaning that they are not beneficial moves according to the DMs' attitudes presented in this scenario and omitted. The stability of state 9 for $\mathrm{CO} 2$, for instance, is investigated. $\mathrm{CO} 2$ wants to move only to the states that:

1. Will not benefit the opponent;

2. Will benefit itself at the same time.

This is because CO2 has a negative attitude towards $\mathrm{CO} 1$. If the ordering of the states for $\mathrm{CO} 2$ in Figure 6 is considered, it can be observed that although $\mathrm{CO} 2$ benefits from changing the position from state 9 to state 15, CO1 also benefits from this move (15 is preferred to 9 for CO1). However, this move is in contradiction to the negative attitude of $\mathrm{CO} 2$ towards $\mathrm{CO} 1$; as such, this possible move is not made by $\mathrm{CO} 2$ and is consequently crossed out by an "X". Taking into account the second move for $\mathrm{CO} 2$ from state 9 , when CO2 moves from state 9 to state 4 in order to benefit itself (i.e., $\mathrm{CO} 2$ has a positive attitude towards itself), this move can lower the CO1's position, because state 4 is not preferred to state 9 for CO1, as shown in Figure 6. Therefore, this move is not considered a possible move for $\mathrm{CO} 2$. If the states are analyzed one by one for each DM, similar moves-countermoves simulation is conducted for every remaining state to determine which possible and feasible moves each DM from each state can count on.

Once the possible moves of the DMs, according to their attitudes, are recognized, the solution concepts introduced in Table 1 are used to carry out the stability analysis. The solution concepts help the analyst determine the type of stability for each state based on the attitudes of DMs. The stability of state 9 , for instance, is assessed for both DMs in this scenario. From CO1's point of view, no possible move exists from state 9. According to the definition, this state is Nash stable for CO1 and "RNASH" is written in the CO1's stability, as shown in Figure 6. Also, because CO1 has negative attitude towards CO2, all possible moves beneath 9 have already been crossed out and omitted. If the moves of $\mathrm{CO} 2$ are taken into account, CO2 can only move from state 9 to state 4 . In this case, CO1 moves from state 4 to state 5 , because state 5 is preferred to state 9 for $\mathrm{CO} 2$. Therefore, $\mathrm{CO} 2$ will choose to move to state 4 , which is an

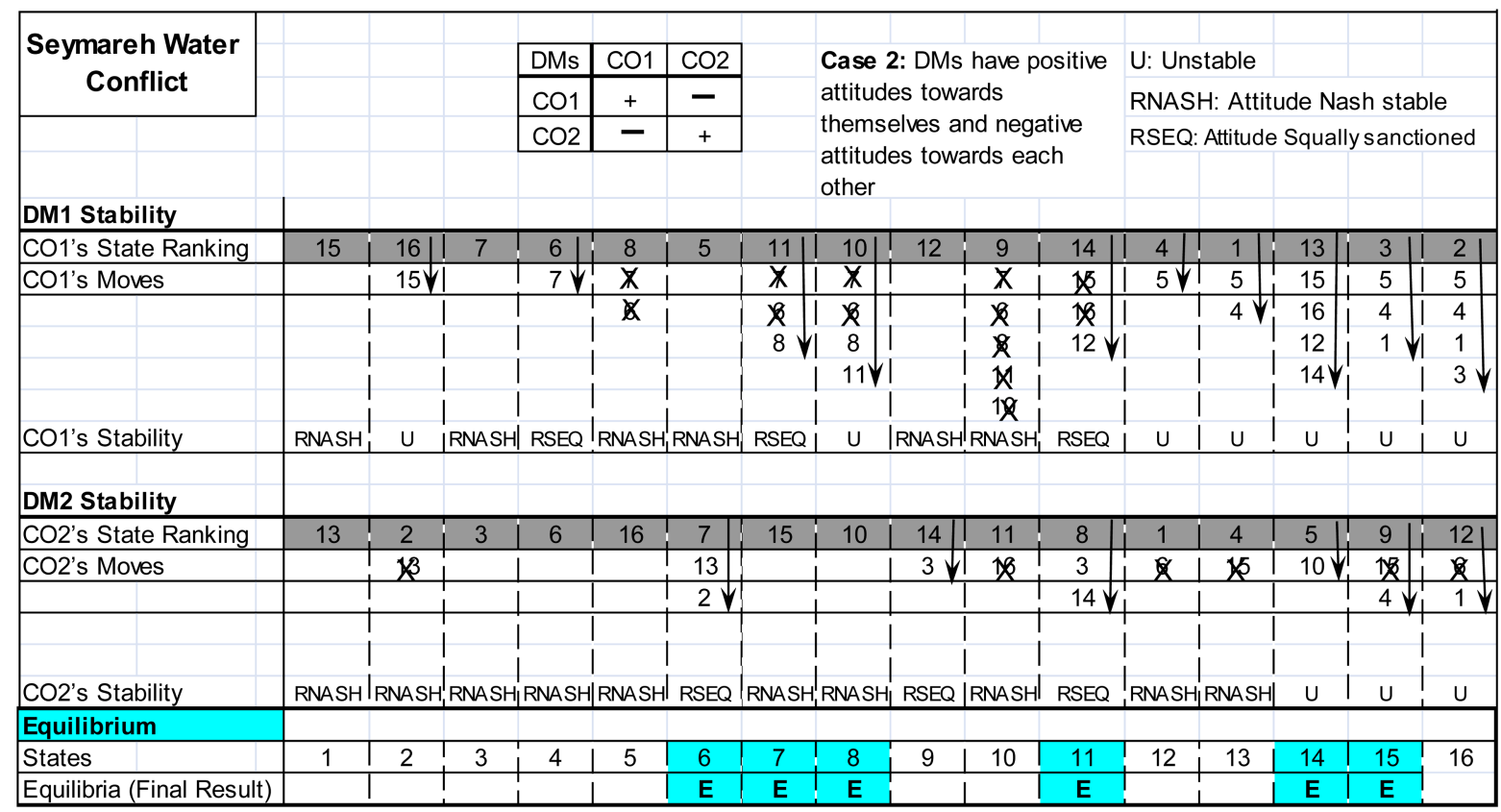

Figure 6. Stability analysis tableau with negative attitudes of DMs towards each other. 
unstable state for CO2. Thus, a "U" is indicated below state 9 in CO2's stability row, as shown in the bottom of Figure 6. Similar to the above explanation, the stability analysis is carried out for the remaining states for each DM in this case study and accordingly, the type of stability for each state and each DM is determined. The results of the moves-countermoves simulation indicate that states $6,7,8,11,14$, and 15 (indicated by "E" at the bottom of Figure 6) are equilibrium states. It should be reminded that in the first scenario explained above, different equilibrium states $(6,7$, and 15$)$ were obtained. This fact indicates that any change in the attitudes of DMs will cause corresponding change in equilibrium states resulting from the stability analysis.

Scenario 3: DMs possess positive attitudes towards each other. In the above discussions, the DMs in Scenario 1 and Scenario 2 had neutral and negative attitudes towards each other, respectively. In Scenario 3, a situation is considered in which both DMs have positive attitudes towards each other while the attitudes towards themselves remain positive. This scenario is in contrast to Scenario 2 in terms of DMs' attitudes and the goal is to examine the relationship between changes in the strategic negotiation outcomes and changes in the DMs' attitudes. The stability procedure is explained in Figure 7.

Some moves are crossed out by an "X" according to the DMs' positive attitudes (Figure 7). In order to clarify why these states are crossed out in this scenario, state 11 for CO1, as an example, is considered. Since CO1 has a positive attitude towards $\mathrm{CO} 2$, only the moves that benefit both DMs are considered. CO1 can move from 11 to 7 and/or 6 since such moves benefit both DMs. However, moving from 11 to 8 will lower CO2's position in its state ranking and this contradicts its attitude towards CO2. Thus, CO1 will not consider moving to 8 and an " $\mathrm{X}$ " is written on 8 underneath 11 in CO1's state ranking. A similar procedure is conducted for the remaining states in order to determine the possible moves for each DM when positive attitudes are governed.

Upon obtaining the DMs' attitude-based moves, the type of stability for each state is determined in terms of the attitudes of the DMs. As an example, the stability of state 11 is assessed for both DMs. From CO1's perspective, there are two possible moves from 11 , which are 7 and 6 . If CO1 moves from 11 to 7 or 6 , $\mathrm{CO} 2$ cannot make a countermove, because 7 and 6 are Nash stable for CO2. Thus, state 11 is unstable for CO1 and a "U" is written in CO1's stability row in Figure 7. From CO2's perspective, the only possible option is to move from 11 to 16 . If this move takes place, then CO1 cannot make a countermove from 16 , because 16 is Nash stable for CO1; as such, state 11 is unstable for $\mathrm{CO} 2$ and a "U" is written in CO2's stability row in Figure 7.

Similar to the procedure explained for state 11 , stability analysis is conducted for the remaining states in order to define the type of stability for each state and consequently obtain equilibrium states for this scenario. The final resulting outcome of this attitude scenario indicates that states $1,3,5,6,7,13,15$, and 16 (indicated by "E" at the bottom of Figure 7) are equilibria or equilibrium states. It should be noted that in Scenario 1 and Scenario 2, different equilibrium states were obtained. This fact once again

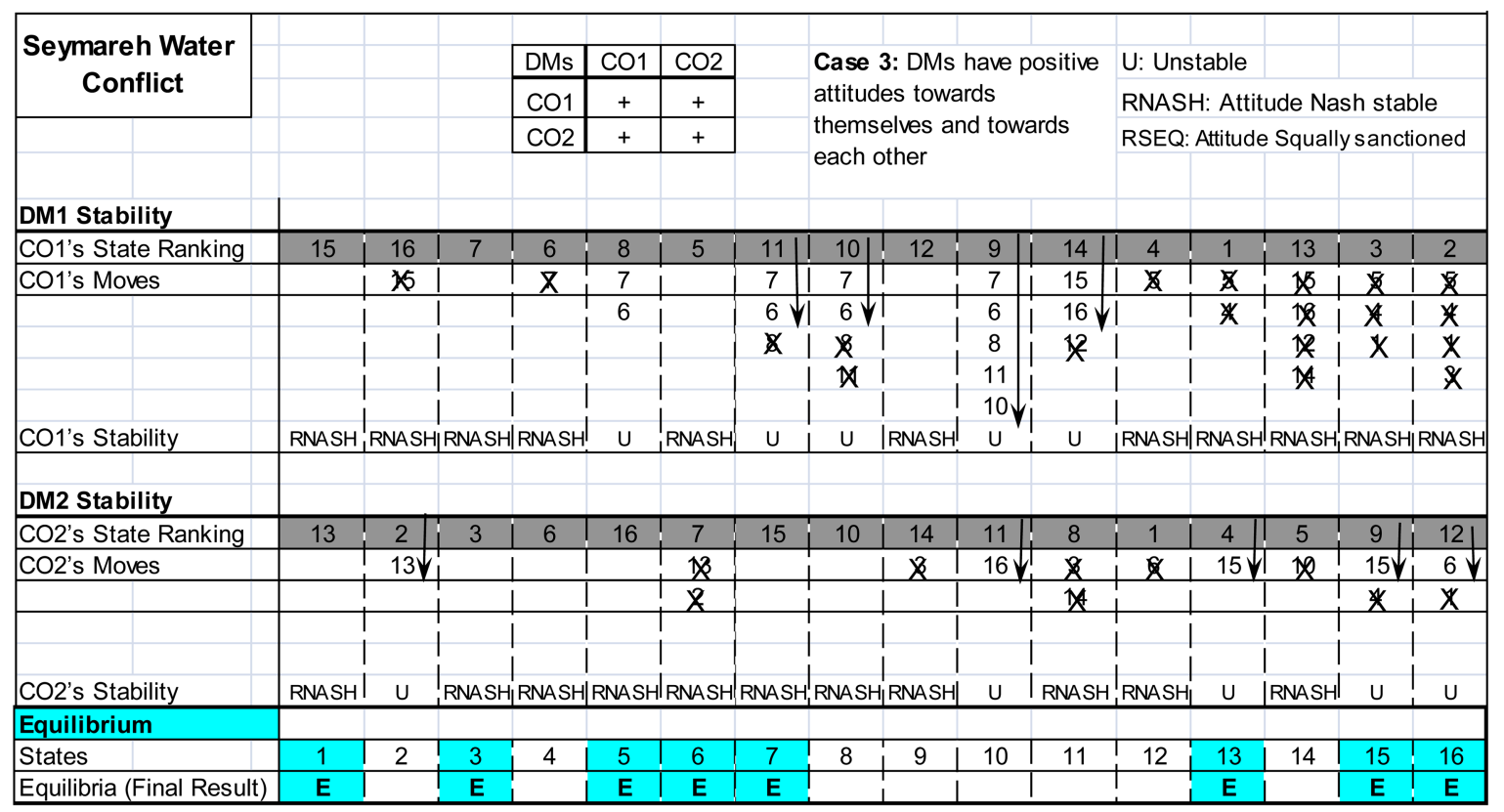

Figure 7. Stability analysis tableau with positive attitudes of DMs towards each other. 
shows that the change in the DMs' attitudes causes a corresponding change in the resulting equilibrium states.

Step 6: Discussion of the results. In the previous steps, three attitude scenarios were considered. In Scenario 1, the DMs possessed neutral (rational) attitudes towards each other; in Scenario 2, the DMs possessed negative attitudes towards each other; and in Scenario 3, the DMs possessed positive attitudes towards each other. In all scenarios, it was logically assumed that the DMs maintained positive attitudes towards themselves. The objective of this step is to investigate and examine how changes in the DMs' attitudes during a complex dispute with dynamic nature can affect the outcomes of dispute resolution process. The resulting outcomes for the three attitudes scenarios are summarized in Figure 8. The results indicate that:

1. When the DMs possess neutral attitudes towards each other, states 6,7 , and 15 are a set of equilibria (possible dispute solutions). They are fairly in the middle of state ranking row for both DMs. Among the three resulting states, one of them may be mutually chosen by the DMs as the final solution to their dispute;

2. Based on the dynamic situation of the dispute and after some rounds of negotiation, the DMs may take hostile actions against each other. In this situation, the DMs decide to shift their attitudes towards each other from neutral to negative and, as a result, the solution states (e.g., states 6, 7, 8, 11, 14, and 15) that represent more hostile solutions are obtained. Comparing the sets of resulting states, it is observed that the states 6,7 , and 15 are common between the two scenarios. In Figure 6 , it is also noticed that the set of equilibria is slightly shifted towards the right side where non-preferred states are ranked by the DMs;
3. Now, if the situation of dispute turns to a more helpful condition and the DMs try to better understand each other during the negotiation rounds, then the DMs' attitudes towards each other turn to be positive. In this condition, a set of equilibria is reached that is relatively shifted towards the left side of the DMs' state ranking, meaning that both DMs prefer a solution to the conflict, which is more beneficial for both of them. Among the three sets, states 6,7 , and 15 are common;

4. With the increase in the number of resulting states or the number of resolutions, the analyst (who studies the conflict in order to propose a solution) is able to suggest a wider range of possible solutions to the involved DMs;

5. With respect to the third scenario, when the DMs possess positive attitudes towards themselves and each other, it is observed that the hostility of some outcomes (e.g., states 13 and 14) is mitigated;

6. In the case of positive attitudes (Figure 7), the sets of solutions represented in both DMs' state ranking rows are shifted from the right, i.e., the less preferred states, to the left, i.e., the more preferred states. In other words, the positive attitudes of the DMs directly influence the dispute resolution outcomes, which is more preferred by the DMs;

7. Figure 8 highlights an important observation, that is, the set of resolutions 6,7 , and 15 are the only equilibrium states that are common among the three attitude cases. The equilibrium states 6,7 , and 15 represent the most stable outcomes of this real-life case study. In other words, three stable states (as possible outcomes) are obtained based on the stability analysis. They are stable because, regardless of what types of attitudes (neutral, negative, or positive) the DMs possess towards each other, they appear as possible resolutions (Figure 8).

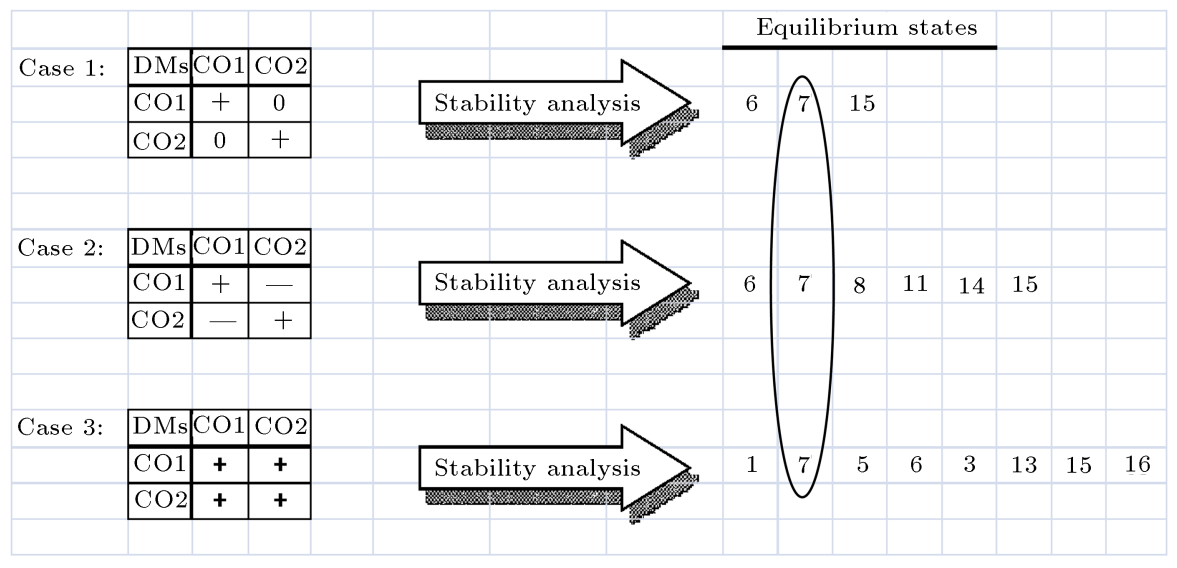

Figure 8. Three attitude cases and the corresponding resulting outcomes. 
Step 7: Recommendation of a tangible resolution. Using the GMCR paradigm, the real case study has so far been modeled and analyzed, and the outcomes derived from the three attitude scenarios are discussed. In this step, the involved DMs expect the analyst to provide them with a solution that is easy to understand, tangible, practical, and beneficial for both CO1 and CO2. According to this logical expectation, the analyst examines all the resulting outcomes from the three attitude scenarios and observes that states 6 , 7 , and 15 are the most stable states because, no matter how the attitudes of $\mathrm{CO} 1$ and $\mathrm{CO} 2$ towards each other change, these three states appear as possible solutions to this dispute. Therefore, the analyst focuses more on the three states. In a step forward to select one final solution among these three possible solutions, the analyst tries to understand what states 6,7 , and 15 exactly mean. As shown in Table 3 , state 6 means that CO1 takes the case to court (litigation), does not share costs, and does not make the water treatment of the reservoir and $\mathrm{CO} 2$ does not continue polluting the river because it receives partial financial and technological supports from other governmental agencies. State 7 means that CO1 does not take the case to court, does share the costs of water remediation, and does help water treatment, and $\mathrm{CO} 2$ does not continue polluting the river because it receives partial financial and technological supports from other governmental agencies. State 15 means that CO1 takes the case to court, does not share the costs with other stakeholders, and does help treating water, and CO2 neither continues polluting the river nor receives partial financial supports from different agencies.

Among the three described solutions, state 7 seems the most reasonable solution that can be proposed to the disputing parties in this case study. The suggested solution mutually benefits both parties in which the dam owner (CO1) does not take hostile action by taking the case to court and tries to solve the problem by sharing the costs and treating the polluted water (positive attitude). In return, the upstream province and its local communities along the Seymareh River (CO2) not only stop polluting the river but also arrange to construct facilities along the border of the river to make water treatment (positive attitude). Receiving financial support empowers CO2 to buy and install water treatment facilities. Meanwhile, the proposed solution contains some indirect benefits for both parties such as saving extra costs and time by the dam owner and the opportunity of job creation for the province. It should be mentioned that the recommended option is a resolution for the conflict at the strategic level, as GMCR provides DMs with a guideline and suggests a direction in their negotiation [13]. The mutually agreed-upon solution at the strategic level can be further negotiated at the tactical level in order to exactly determine who is responsible for what part of the solution. More related details can be studied in [26-30].

\section{Conclusions}

A novel negotiation methodology was presented in this research for managing water and environmental disputes that were very complex in nature. The developed methodology benefited from the unique feature of taking into account decision makers' (DMs) attitudes, which is a key factor in dealing with complex water disputes. The methodology was developed within the context of decision making at the strategic level in which the Graph Model for Conflict Resolution (GMCR) was utilized for assisting DMs to arrive at the best strategic decision, considering the DMs' competing needs, wants, interests, and attitudes. A real case study was used to support the convenient application of the proposed methodology in practice and to illustrate the significance and benefits of incorporation of DMs attitudes in a negotiation methodology.

This research significantly contributes to the improvement of managerial decision-making system by meaningfully incorporating DMs' attitudes into a negotiation methodology. Thus, the importance of this research lies in proposing an attitude-based negotiation methodology as a conflict management system. This system assists DMs involved in complex water-related disputes to become aware of the attitudes that are needed in order to conduct the evolution of the conflict for more preferable outcomes and reduce the types of attitudes that may result in unwanted consequences for all stakeholders involved in the negotiation procedure.

\section{References}

1. Peters, N.E., Meybeck, M., and Chapman, D. "The effects of human activities on water quality", In Encyclopedia of Hydrological Sciences, John Wiley and Sons Inc., New York, USA, pp. 1529-1553 (2005).

2. Falkenmark, M. "Forward to the future: a conceptual framework for water dependence. Volvo environment", Prize Lecture 1998, Ambio, 28(4), pp. 356-361 (1999).

3. Doerpinghause, H.I., Schmit, J.T., and Yeh, J.J.H. "Risk aversion, negotiation, and claims settlement strategies", Social Science Research Network, 2008 Social Science Electronic Publishing Inc., New York, USA (2005).

4. Cheung, S., Yiu, K.T.W., and Suen, H. "Construction negotiation online", Journal of Construction Engineering and Management, 130(6), pp. 844-852 (2004).

5. Fang, L., Hipel, K.W., and Kilgour, D.M., Interactive Decision Making: The Graph Model for Conflict Resolution, pp. 112-161, ISBN: 0-471-59237-4, Wiley and Sons, New York, USA (1993). 
6. Hipel, K.W., Jamshidi, M.M., Tien, J.M., and White III, C.C. "The future of systems, man and cybernetics: application domains and research methods", IEEE Transactions on Systems, Man, and Cybernetics, Part C, Applications and Reviews, 37(5), pp. 726-743 (2007). DOI: 10.1109/TSMCC.2007.900671

7. Yousefi, S., Hegazy, T., and Hipel, K.W. "Considering attitudes in strategic negotiation over brownfield disputes", The American Society of Civil Engineering (ASCE), Journal of Legal Affairs and Dispute Resolution in Engineering and Construction, 2(4), pp. 240248 (2010).

8. Pinnell, S. "Partnering and the management of construction disputes", Dispute Resolution Journal, 54(1), pp. 16-22 (1999).

9. Harmon, K.M.J. "Resolution of construction disputes: a review of current methodologies", Leadership Management Engineering, 3(4), pp. 187-201 (2003).

10. Richter, I.E. "The project neutral: neutralizing risk, maintaining relationships and watching the bottom line", Construction Business Review, 8(2), pp. 52-56 (2000).

11. Hipel, K.W., Ed., Conflict Resolution, 1, Eolss Publishers, Oxford, United Kingdom (ISBN-978-1-84826120-4 (Adobe e-Book), ISBN-978-1-84826-570-7 Library Edition (Hard Cover)) (Earlier versions of the papers appeared in the Encyclopedia of Life Support Systems.) (2009).

12. Hipel, K.W., Ed., Conflict Resolution, 2, Eolss Publishers, Oxford, United Kingdom (ISBN-978-1-84826121-1 (Adobe e-Book), ISBN-978-1-84826-571-4 Library Edition (Hard Cover)) (Earlier versions of the papers appeared in the Encyclopedia of Life Support Systems) (2009).

13. Kilgour, D.M., Diplomacy Game: The Graph Model for Conflict Resolution as a Tool for Negotiators, Part IV, pp. 251-263, Springer Berlin Heidelberg, Germany (2007).

14. Howard, N., Paradoxes of Rationality: Theory of Metagames and Political Behavior, MIT Press, Cambridge, Massachusetts, USA (1971).

15. Fraser, N.M. and Hipel, K.W., Conflict Analysis: Models and Resolutions, North Holland, pp. 10-370, ISBN: 0-444-00921-3, New York, USA (1984).

16. Hipel. K.W., Hegazy, T., and Yousefi, S. "Combined strategic and tactical negotiation methodology for resolving complex brownfield conflicts", The Brazilian Journal of Operational Research, Special Issue of Pesquisa Operational on Soft OR and Complex Societal Problems, 30(2), pp. 281-304 (2010).

17. Hipel, K.W. and Fang, L. "Multiple participant decision making in societal and technological systems", In Systems and Human Science - For Safety, Security, and Dependability: Selected Papers of the 1st International Symposium, SSR2003, Chapter 1, T. Arai, S. Yamamoto, and K. Makino, Eds., Osaka, Japan, published by Elsevier, Amsterdam, The Netherlands, pp. 3-31 (2005).
18. Nash, J.F. "Equilibrium points in n-person games", Proceedings of National Academy of Sciences, 36, pp. 48-49 (1950).

19. Nash, J.F. "Non-cooperative games", Annals of Mathematics, 54(2), pp. 286-295 (1951).

20. Fang, L., Hipel, K.W., Kilgour, D.M., and Peng, X. "A decision support system for interactive decision making. Part 1: Model formulation", IEEE Transactions on Systems, Man and Cybernetics, Part C: Applications and Reviews, 33(1), pp. 42-55 (2003). DOI: 10.1109/TSMCC.2003.809361

21. Fang, L., Hipel, K.W., Kilgour, D.M., and Peng, X. "A decision support system for interactive decision making. Part 2: Analysis and output interpretation", IEEE Transactions on Systems, Man and Cybernetics, Part C: Applications and Reviews, 33(1), pp. 56-66 (2003). DOI: 10.1109/TSMCC.2003.809360

22. Inohara, T., Hipel, K.W., and Walker, S. "Conflict analysis approaches for investigating attitudes and misperceptions in the war of 1812", Journal of Systems Science and Systems Engineering, 16(2), pp. 181-201 (2007). DOI: $10.1007 / \mathrm{s} 11518-007-5042-\mathrm{x}$

23. Plaut, E. "Iran industry spotlight: Water management", American-Iranian Council Website, http:// www.us-iran.org/resources/2017/7/24/industryspotlight-water-management (2017).

24. IWPCO, Iran Water and Power Resources Development Company (IWPCO), Accessed website on April 10, 2013: http://en.iwpco.ir/default.aspx (2013).

25. Hamouda, L., Kilgour, D.M., and Hipel, K.W. "Strength of preference in the graph model for conflict resolution", Group Decision and Negotiation, 13(5), pp. 449-462 (2004). DOI: 10.1023/B:GRUP.0000045751.21207.35

26. Yousefi, S. and Bozorgzad, E. "Negotiations for conflict management during impoundment of large dams", The Proceedings of International Symposium on Dams for a Changing World, Annual Conference of International Commission on Large Dams (ICOLD), Kyoto, Japan, June 2-6, pp. 2-65 to 2-70 (2012).

27. Yousefi, S., Hipel, K.W., and Hegazy, T. "Attitudebased negotiation methodology for the management of construction disputes", Journal of Management in Engineering, 26(1), pp. 114-122 (2010). DOI: 10.1061/(ASCE)ME.1943-5479.0000013

28. Hipel, K.W., Kilgour, D.M., Fang, L., and Peng, X. "The decision support system GMCR in environmental conflict management", Applied Mathematics and Computation, 83(2 and 3), pp. 117-152 (1997). DOI: 10.1016/S0096-3003(96)00170-1

29. Xu, H., Hipel, K.W., Kilgour, D.M., and Fang, L. "Conflict resolution using the graph model: Strategic interactions in competition and cooperation", In The Series on Studies in Systems, Decision and Control, Springer, Heidelberg, Germany (2018).

30. Yousefi, S., Hajimirzaie, S.M., and Hosseinipour, E.Z. "Attitude-based negotiations for resolving water and 
environmental conflicts", The ASCE World Environmental and Water Resources Congress, Florida, USA, May 22-26, pp. 47-56 (2016).

\section{Biographies}

Saied Yousefi has been active in the area of construction project management for 23 years in both industry and academy. He is currently an assistant professor of project management and construction at University of Tehran in Iran and a faculty member of the Conflict Analysis Group in the Department of Systems Design Engineering at the University of Waterloo in Canada, where he received his $\mathrm{MSc}, \mathrm{PhD}$, and Postdoc all in construction project management. Received his Project Management Professional (PMP) designation from the USA, Dr. Yousefi's main research focus is on soft skills of project management such as development of negotiation and conflict management methodologies. $\mathrm{He}$ is the recipient of the 2011 best paper award from American Society of Civil Engineers (ASCE) and the winner of Visiting International Fellowship (VIF) award from the Environmental and Water Resources Institutes (EWRI) in the USA. He has published several papers in international journals. Dr. Yousefi is a steering committee member of the International Conference on Water Resources and Environmental Research and a member of some international institutions. He has consulted and advised numerous contractors and government organizations in Iran.

Keith W. Hipel is a professor of Systems Design Engineering at the University of Waterloo, where he is also Coordinator of the Conflict Analysis Group. He is past President of the Academy of Science within the Royal Society of Canada, Senior Fellow of the Centre for International Governance Innovation, Fellow of the Balsillie School of International Affairs, and Past Chair of the Board of Governors of Renison University College. Dr. Hipel thoroughly enjoys mentoring students and is a recipient of the Distinguished Teacher Award, Faculty of Engineering Teaching Excellence Award, and the Award of Excellence in Graduate Supervision from the University of Waterloo as well as the Outstanding Engineering Educator Award from IEEE Canada. His major research interests are the development of conflict resolution, multiple criteria decision analysis, time series analysis, and other decision-making methodologies for addressing the challenging interdisciplinary systems engineering problems lying in the confluence of society, technology, and the environment, with applications in water resources management, hydrology, environmental engineering, energy, and sustainable development. Prof. Hipel is the recipient of the Japan Society for the Promotion of Science (JSPS) Eminent Scientist Award, Joseph G. Wohl Outstanding Career Award from the IEEE Systems, Man and Cybernetics (SMC) Society, IEEE SMC Norbert Wiener Award, Docteur Honoris Causa (France), Doctor Honoris Causa (Hungary), Sir John William Dawson Medal (Royal Society of Canada), Engineering Medal for Research and Development (Professional Engineers Ontario), and the Foreign Member designation with the National Academy of Engineering (NAE) of the United States of America.

Tarek Hegazy has participated in a wide spectrum of new/rehabilitation projects and is internationally renowned for his research on computational construction management and asset management. His recent research has used tools of computational intelligence to efficiently plan and execute municipal infrastructure programs and support contractors' decisions in highrisk and constrained projects. Dr. Hegazy is the sole author of the textbook "Computer-Based Construction Project Management" published by Prentice Hall. He has supervised many $\mathrm{PhD}$ and MSc students and now collaborates with many universities worldwide. He has received several awards of excellence in research. In 2004, Dr. Hegazy was acknowledged as one of the world's top five contributing authors to ASCE construction research (ranked third in the period 19972002), as reported in the Journal of Construction Engineering and Management article, Vol. 130, No. 3, 2004, page 437 . Dr. Hegazy has two patents, a best paper award in 2011 from the Journal of Management in Engineering, ASCE, and a top cited paper award from the Advanced Engineering Informatics Journal. He has consulted and advised a number of contractors and government organizations in Canada. He is the founder of OPTEAM Project Management Consultants Inc. 